\title{
A collaborative care management programme in a primary care setting was effective for older adults with late life depression
}

Unützer J, Katon W, Callahan CM, et al. Collaborative care management of late-life depression in the primary care setting: a randomized controlled trial. JAMA 2002;288:2836-45.

\section{QUESTION: Is a collaborative care management programme offered in a primary care setting effective for older adults with late life depression?}

\section{Design}

Randomised (allocation concealed), blinded (outcome assessors) controlled trial with 1 year of follow up.

\section{Setting}

18 primary care clinics from 8 healthcare organisations in 5 states in the US.

\section{Patients}

1801 patients $\geq 60$ years of age (mean age 71 y, $65 \%$ women) who met the Diagnostic and Statistical Manual of Mental Disorders, $4^{\text {th }}$ edition criteria for major depression or dysthymia or both and who were planning to use general medical care from a participating clinic. Exclusion criteria were drinking problems, bipolar disorder or psychosis, severe cognitive impairment, or acute risk of suicide. Follow up was $98 \%$.

\section{Intervention}

906 patients were allocated to the Improving MoodPromoting Access to Collaborative Treatment (IMPACT) management programme, which comprised $\leq 12$ months of access to a depression care manager (a nurse or psychologist who was supervised by a psychiatrist and a liaison primary care physician). The depression care manager worked with the patient and primary care practitioner to prepare a treatment plan based on the treatment choice of the patient and the patient's primary care practitioner: antidepressant treatment or brief structured psychotherapy (Problem Solving Treatment in Primary Care [PST-PC]). 895 patients were allocated to usual care.

\section{Main outcome measures}

Treatment response, defined as a $\geq 50 \%$ reduction in the baseline Symptom Checklist (SCL)-20 score (20 depression items from the SCL-90); complete remission of depressive symptoms, defined as a SCL-20 score $<0.5$; self reported use of antidepressants or psychotherapy; health related functional impairment; and quality of life.

\section{Main results}

$17 \%$ of participants had major depression, $30 \%$ had dysthymic disorder, and 53\% had major depression and dysthymic disorder. Analysis was by intention to treat. The intervention group had higher rates of treatment response, complete remission of depressive symptoms, and any use of antidepressant medications or psychotherapy (table) than the usual care group. Also, the intervention group had less health related functional impairment $(p<0.001)$ and greater quality of life $(\mathrm{p}<0.001)$ than those in the usual care group.

\section{Conclusion}

In older adults with late life depression, a collaborative care management programme offered in a primary care setting increased treatment response, remission of depressive symptoms, use of antidepressants or psychotherapy, and quality of life, and reduced functional impairment.
Sources of funding:

John A Hartford Foundation, Hogg Foundation, California Healthcare Foundation, and Robert Wood Johnson Foundation

For correspondence:

Dr J Unützer, Center for Health Services

Research, UCLA

Neuropsychiatric

Institute, Los Angeles,

CA, USA.

unutzer@ucla.edu.

A collaborative care management programme (intervention) v usual care for late life depression*

\begin{tabular}{|c|c|c|c|c|}
\hline $\begin{array}{l}\text { Outcomes at } 12 \\
\text { months }\end{array}$ & Intervention & Usual care & RBI (95\% Cl) & NNT (CI) \\
\hline Treatment response & $45 \%$ & $19 \%$ & $132 \%$ (99 to 172$)$ & $4(3$ to 5$)$ \\
\hline $\begin{array}{l}\text { Complete remission } \\
\text { of depression } \\
\text { symptoms }\end{array}$ & $25 \%$ & $8.3 \%$ & $201 \%$ (135 to 286 ) & $6(5$ to 8$)$ \\
\hline $\begin{array}{l}\text { Any antidepressant } \\
\text { or psychotherapy } \\
\text { use }\end{array}$ & $82 \%$ & $61 \%$ & $35 \%$ (27 to 44$)$ & $5(4$ to 6$)$ \\
\hline
\end{tabular}

*Abbreviations defined in glossary; RBI, NNT, and $\mathrm{Cl}$ calculated from data in article.

\section{COMMENTARY}

Although depression in older adults can be treated successfully, few receive adequate care. $^{1} 2$ known contributors to inadequate care include lack of knowledge about treatment options and the complexity of the healthcare system, which makes it difficult for older adults to access appropriate mental health services. ${ }^{1}$ The intervention tested in the study by Unützer $e t$ al addresses both of these factors. A major strength of the design is the large sample size recruited from a range of primary care clinics serving diverse populations. The positive treatment response to the IMPACT intervention is encouraging given that $83 \%$ of the sample had some degree of dysthymia, a chronic type of depression.

The results of this study are especially relevant to nurse care managers and practitioners who interact with older adults in primary care clinics. Many components of the IMPACT intervention, including the health history, review of educational materials, discussion of treatment options, and telephone follow up, are already part of the care manager and nurse practitioner role. In primary care clinics without a mental health nurse care manager or practitioner, continuing education about depression in older adults would be necessary to enhance the knowledge of non-specialist health practitioners. The PST-PC (6-8 sessions of brief structured psychotherapy) is a key component of the IMPACT intervention. It provides a treatment alternative for older adults who are reluctant to take medication because of the stigma associated with depression or medication side effects, and those who have concurrent medical conditions that may interfere with a therapeutic response to antidepressants. Provision of treatment at the primary care level should improve access to mental health care for older adults. However, implementing the PST-PC may be challenging because of the constraints of time, money, and staff expertise in some clinics.

Lynda Slimmer, RN, PhD Coordinator, Research Subject Advocacy Program University of Illinois at Chicago Chicago, Illinois, USA

1 NIH consensus conference. Diagnosis and treatment of depression in late life. JAMA 1992;268:1018-24. 